
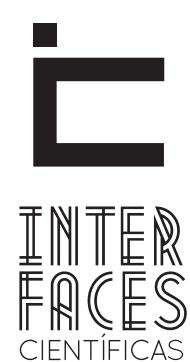

EDUCAÇÃO

ISSN IMPRESSO 2316-333X

ISSN ELETRÔNICO 2316-3828

DOI 10.17564/2316-3828.2015v3n3p87-96

\title{
ANÁLISE DA TRAJETÓRIA DE FORMAÇÃO DE PROFESSORES DE LIBRAS, DE UNIVERSIDADES PÚBLICAS PARANAENSES
}

Josiane Junia Facundo ${ }^{1}$

Marieuza Endrissi Sander ${ }^{2}$

\section{RESUMO}

Esse artigo apresenta uma pesquisa realizada com professores de Língua Brasileira de Sinais - Libras de algumas Universidades públicas estaduais do Paraná. Por meio da análise do currículo da plataforma Lattes, buscou-se estudar a trajetória de formação dos referidos professores, tanto da formação acadêmica como na profissional, levando em conta o tempo de atuação na área educacional e na docência em Libras. As bases teóricas se fundamentam na literatura referente à Formação de professores e no Decreto nº 5626/05, que regulamenta a Lei $n^{0} 10.436 / 02$ e traz os principais pontos de debate para o presente trabalho que põe em pauta a discussão acerca da formação do professor de Libras.

\section{PALAVRAS-CHAVE}

Libras. Formação de Professores. Universidade. 


\section{ABSTRACT}

This paper presents a research with teachers of $\mathrm{Li}$ bras at some public universities on the Paraná state. Through the analysis of the curriculum of the Lattes Platform, we sought to study the formation path of those teachers, both in the academic and professional, taking into account the time of operation in education and teaching in Libras. The theoretical foundations are based on the literature related to teacher

\section{RESUMEN}

En este artículo se presenta un estudio de los profesores de Lengua de Signos Brasileña - Libras de algunas universidades públicas estatales de Paraná. A través del análisis del plan de estudios de la plataforma Lattes, hemos tratado de estudiar la trayectoria de la formación de los maestros, la formación académica y profesional, teniendo en cuenta el momento de la operación en la educación y la enseñanza en Libras. Los fundamentos teóricos se basan en la literatura education and Decree 5626/05, which regulates Law $10.436 / 02$ and brings the main points of discussion for this job putting on the agenda the discussion of teacher Libras.

\section{KEYWORDS}

Libras. Teacher Training. University. sobre la formación del profesorado y el Decreto $\mathrm{N}$ o $5626 / 05$, que reglamenta la Ley $N{ }^{\circ} 10.436 / 02$ y trae los principales puntos de debate de este trabajo poner en agenda la discusión del professor de Libras.

\section{PALABRAS CLAVE}

Libras. Formación del Profesorado. Universidad. 


\section{INTRODUCÇÃO}

A constituição humana se dá em um complexo emaranhado de relações, do qual resulta sua subjetividade, e esta, passa a compor esse mesmo complexo na construção de novas subjetividades. Tomando por base a afirmativa de Santos Neto (2002) de que, a sala de aula abriga um encontro de complexidades humanas no concreto do contexto histórico e social, tendo em vista o encontro da complexidade do professor com a do aluno e do grupo, não se pode ignorar a construção da subjetividade do docente que, como bem pontua Paro (2008) é aquele que tem a capacidade de fazer dos seres humanos, indivíduos dotados de historicidade, e ao modificar o comportamento do aluno, constitui a própria mediação para a modificação.

Concebemos a sala de aula como espaço de formação, numa perspectiva multidirecional, no entanto, o professor é aquele que irá mediar a aprendizagem por meio da sistematização do conhecimento historicamente acumulado pela humanidade. Essa mediação, porém, não é neutra, porque envolve os aspectos da formação do professor, no que se refere à sua visão de mundo e de educação.

Há, portanto, que se valorizar os aspectos humanos da formação docente, que, como afirma Santos Neto (2002, p.45) "articulam-se com a racionalidade técnica, política e profissional”. Nesse sentido, concebemos que a trajetória de formação do professor pode dar pistas significativas acerca de suas concepções e tendências que irão direcionar suas escolhas metodológicas ou de conteúdo.

Nessa mesma perspectiva, Nóvoa (1995) considera a importância de se resgatar as histórias de vida dos professores, propondo um roteiro para construir a biografia educativa desses docentes.

Diante dessas considerações, buscamos, neste trabalho, realizar um estudo da trajetória de formação dos professores de Libras, considerando não apenas a formação acadêmica, mas, também, profissional, uma vez que, como assinala Imbernón (2009, p.16), "a aquisição de conhecimentos por parte do professor está muito ligada à prática profissional, e condicionada pela organização da instituição educacional em que esta é exercida”.

\section{CONSIDERACÕES ACERCA DOS PROCESSOS DE FORMACÃO DOCENTE E PROFISSIONAL}

Em documentos legais, relacionados à educação, a formação docente é expressivamente referenciada, em termos quantitativos. Romanowski (2007, p.98) salienta que, soma- se às determinações legais a reestruturação social, pois há consenso no entendimento de que o professor ainda é peça-chave na educação escolar, uma vez que "quem atua na prática escolar, possibilitando qualquer mudança ou inovação, a grosso modo, é o professor" (ROMANOWSKI, 2007, p.99).

Embora em algum momento houvesse o pensamento de que a tecnologia substituiria o professor, como a robótica nas indústrias de produção em série; hoje, sabemos que a formação humana só pode e deve ser feita por sujeitos que pensem por si próprios, capazes de distinguir e perceber os alunos de acordo com sua singularidade, atuando com a subjetividade humana.

Há, também, ampla produção acadêmica acerca do tema formação de professores, no entanto, os esforços e investimentos em geral destinados a essa formação ainda estão bastante distantes dos discursos.

Com a valorização do sujeito, de sua participação social, bem como a relevância da bagagem sociocultural na educação, tendo em vista uma educação democrática, (IMBERNÓN, 2009, p.11) faz-se necessária uma renovação da escola e dos professores frente 0 compromisso com a formação desse cidadão. 
Nas palavras de Imbernón:

Essa necessária renovação da instituição educativa e esta nova forma de educar requerem uma redefinição importante da profissão docente e que se assumam novas competências profissionais no quadro de um conhecimento pedagógico, científico e cultural revistos. Em outras palavras, a nova era requer um profissional da educação diferente. (IMBERNÓN, 2009, p.12)

\section{De acordo com Romanowski,:}

No pensamento de Morin a educação para o futuro está alicerçada no entendimento do conhecimento pertinente, contextualizado, multidimensional, interdependente, interativo e globalizado, portanto, não acontece de modo fragmentado e particular. É necessário, segundo o autor, que a condição humana, física, biológica, psicológica, cultural, social e histórica, a identidade terrena e a compreensão mútua constituam os indicativos para educação do futuro. Tudo isso e uma educação para a incerteza que tenha como meta a formação do cidadão ético são condições para pensar a formação de professores. (ROMANOWSKI, 2007, p.120)

Imbernón (2009, p.14) considera, ainda, que a profissão docente hoje não se restringe à mera transmissão de conhecimento científico, mas inclui o engajamento na luta contra a exclusão social, a motivação do aluno, entre outras atribuições, o que requer "uma nova formação: inicial e permanente"

A formação inicial do professor deve considerar os aspectos éticos, voltados às relações humanas que se tecerão no cotidiano escolar e visando à transformação da sociedade, cujos valores contribuam, a priori, para o bem-estar social em detrimento do individual.

Os estudos recentes de formação docente consideram que o professor não é constituído somente do aspecto profissional, mas também pela dimensão humana em que se leva em conta a história de vida ou a constituição pessoal desse sujeito. Nos dizeres de Nóvoa:
Hoje sabemos que não é possível separar o eu pessoal do eu profissional, sobretudo numa profissão fortemente impregnada de valores e ideais e muito exigente do ponto de vista do empenhamento e da relação humana. Houve um tempo em que a possibilidade de estudar o ensino, para além da subjetividade do professor, foi considerada um sucesso científico e um passo essencial em direção a uma ciência da educação. Mas as utopias racionalistas não conseguiram pôr entre parênteses a especificidade irredutível da ação de cada professor, numa óbvia relação com as características pessoais e com as suas vivências profissionais como escreve Jennifer Nias: "O professor é a pessoa; e uma parte importante da pessoa é o professor". (NÓVOA apud NETO, 2002, p.44)

A formação inicial deve, também, trazer a realidade escolar ao graduando, uma vez que este ainda não atua profissionalmente, embora haja algumas exceções. Mas, para que seja possível um olhar crítico sobre a realidade escolar, é necessário que se criem espaços de debates sobre as questões que perpassam o ambiente educativo. Como reforça Imbernón (2009, p.61), “a estrutura da formação inicial deve possibilitar uma análise global das situações educativas que, devido à carência ou à insuficiência da prática real, se limitam predominantemente a simulações dessas situações". 0 autor ainda sugere que se estabeleça uma formação que leve o aluno a "valorizar a necessidade de uma atualização permanente em função das mudanças que se produzem".

Isaia (2006, p.67) assinala que "a formação permanente, para se consolidar, precisa ser entendida como um processo organizado, sistemático e intencional, a partir do grupo de professores, das instituições e das políticas educativas de nível superior." O que a autora coloca em relação à formação do professor de ensino superior, acreditamos valer para a formação docente nos diferentes níveis de ensino.

Imbernón (2009, p.48) destaca cinco grandes eixos de formação permanente do professor, quais sejam "a reflexão prático-teórica sobre a própria prática” que coloca o professor em posição ativa diante de sua própria realidade educacional, gerando conhecimentos 
a partir de sua prática educativa; a "troca de experiências entre iguais" visando atualização por parte do professor em todos os campos de intervenção educativa; "a formação como estímulo crítico" diante de situações que envolvem práticas discriminatórias, por exemplo, no ambiente profissional ou social; e "o desenvolvimento profissional da instituição educativa” o qual se efetivaria por meio de um trabalho conjunto.

Na formação permanente, a escola também é vista como espaço de formação. Isaia e Bolzan (2007, p.163) consideram que "é necessário proporcionar, aos professores principiantes e em serviço, apoio e recursos dentro das instituições nas quais atuam, além de ajudá-los a aplicar o conhecimento que já possuem ou podem obter por si mesmos." Nesse contexto, Imbernón salienta que:

\begin{abstract}
[...] não é apenas uma formação como conjunto de técnicas e procedimentos, mas tem uma carga ideológica, valores, atitudes, crenças. Não é, portanto, uma simples transferência física, nem tampouco um novo agrupamento de professores para formá-los, e sim um novo enfoque para redefinir os conteúdos, as estratégias, os protagonistas e os propósitos da formação. (IMBERNON,2009, p.80)
\end{abstract}

As estratégias de formação do professor no próprio ambiente de trabalho vêm ao encontro da necessidade de uma educação de qualidade, visto que, muitos dos profissionais da educação, ao ingressarem na carreira, não buscam por si próprios uma formação continuada que aliada a prática decorrente da profissão docente contribui para a constituição da professoralidade. Nas palavras de Isaia e Bolzan (2007, p.164) "é preciso a vontade do professor para se envolver com atividades de formação e sua decorrente profissionalização, possibilitando a construção de sua professoralidade".

\section{A FORMACX̃O DO PROFESSOR DE LIBRAS NO BRASIL}

As políticas educacionais vigentes no Brasil, especialmente no que se refere à educação inclusiva, tem trazido um novo público para a escola, o qual era antes excluído do sistema, ou tratado à margem das discussões acerca das políticas de educação mais amplas.

Em meio à demanda que a escola passa a atender em cumprimento aos dispositivos legais, estão as pessoas surdas, e muitas para dar continuidade aos seus estudos, visto que a modalidade educacional que as atendia não ofertava níveis mais avançados de ensino até o final dos anos 90.

Os alunos surdos, contudo, ainda se deparam com alguns obstáculos, entre os quais o preconceito no ambiente educacional e o despreparo de alguns educadores em lidar com suas necessidades de aprendizagem. Esses obstáculos humanos são mais difíceis de romper do que as adaptações físicas no ambiente. A mudança de postura frente a esses alunos depende de um trabalho complexo de conscientização dos profissionais da educação (professores e gestores), bem como dos demais alunos, comunidade e outros envolvidos nos trabalhos da escola.

O governo federal, aposta nas Instituições de Ensino Superior para implementar a proposta de educação inclusiva, tendo em vista que "a formação e a capacitação docente impõem-se como meta principal a ser alcançada na concretização do sistema educacional que inclua a todos, verdadeiramente" (BRASIL, 1998, p.17).

Nesse sentido, uma das formas de se garantir formação adequada aos professores que deverão atender a todos os alunos e contribuir para que suas necessidades educacionais sejam garantidas é a oferta de disciplinas específicas dos currículos de formação inicial, das diversas licenciaturas (CAIADO; JESUS; BAPTISTA, 2011). 
Como resultado das políticas de Educação para Todos, aliado à luta da comunidade surda no Brasil; em 2005 foi instituído o Decreto $n^{0} 5.626$, regulamentando a Lei $n^{\circ} 10.436 / 02$, que reconhece a Libras como meio legal de comunicação e expressão. 0 referido decreto ressalta a oferta de ensino bilíngue para surdos e estabelece algumas diretrizes para alcançar tal objetivo. A principal medida do decreto vem ao encontro da formação de professores para atuar junto aos alunos surdos no ensino comum. Para isso, inclui a disciplina de Libras como obrigatória nos currículos das licenciaturas e do curso de Pedagogia.

Essa medida exigiu a reorganização dos Cursos universitários quanto à adequação de sua matriz curricular, bem como da abertura de processos seletivos e concursos públicos para a contratação de docentes para ministrarem a disciplina de Libras.

Quanto ao profissional que deve ministrar a disciplina de Libras, o Decreto $n^{0} 5626 / 05$, não exige inicialmente do docente responsável formação em nível Superior, sendo que o Artigo $7^{\circ}$ abre uma prerrogativa de que nos próximos dez anos, a partir da publicação do Decreto, se não houver docente com título de pós-graduação ou de graduação em Libras para o ensino da referida disciplina em cursos de educação superior, os professores devem se encaixar dentro dos seguintes perfis:

I - professor de Libras, usuário dessa língua com curso de pós-graduação ou com formação superior e certificado de proficiência em Libras, obtido por meio de exame promovido pelo Ministério da Educação;

II - instrutor de Libras, usuário dessa língua com formação de nível médio e com certificado obtido por meio de exame de proficiência em Libras, promovido pelo Ministério da Educação;

III - professor ouvinte bilíngue: Libras - Língua Portuguesa, com pós-graduação ou formação superior e com certificado obtido por meio de exame de proficiência em Libras, promovido pelo Ministério da Educação. (BRASIL, 2005)
Devido à inserção da disciplina de Libras via decreto federal e o curto espaço de tempo para cumprimento das determinações legais, considerando que não havia nesse período cursos em nível de graduação, reconhecidos pelo MEC para formar professores de Libras, vem ocorrendo vários problemas decorrentes da interpretação equivocada, e, de certo modo, possível, do decreto em vigor, em relação à inserção de docentes, sem qualificação para ministrarem a disciplina (REBOUÇAS, 2009).

A pesquisa de Tavares e Carvalho (2010) demonstrou que a proficiência na Libras nem sempre faz parte dos requisitos para a docência na disciplina. Além disso, admite-se profissionais com qualquer formação superior, sem a mínima preparação para a docência, em muitos casos, simplesmente por possuírem o certificado de proficiência.

Observa-se, também, a partir do decreto, a proliferação de cursos de Libras em nível de Especialização, cuja demanda abrange profissionais das diversas áreas, em geral, com pouco ou nenhum conhecimento prévio dessa língua. Ressalto que não se trata de impedir que essas pessoas façam os cursos de Especialização, visto que, sua organização curricular, normalmente, privilegia a formação de profissionais que conheçam as necessidades educacionais dos alunos surdos, contribuindo assim para a sua inclusão social e educacional. No entanto, o decreto abre prerrogativas para que a formação desse profissional seja efetivada mediante cursos de pós - graduação (TAVARES; CARVALHO, 2010).

Diante do disposto no decreto, coube ao Ministério da Educação (MEC) apoiar programas de habilitação profissional, por meio de testes seletivos, em caráter emergencial e da abertura de cursos de formação de professores de Libras para ministrarem a disciplina.

Alguns dos dispositivos para preparação do professor de Libras, e também os principais, são o Exame ProLIBRAS e o curso de Letras LIBRAS, ofertado, ini- 
cialmente, pela Universidade Federal de Santa Catarina (Quadros; Campello, 2010).

Contudo, trata-se de vagas ofertadas via processo seletivo, o que consequentemente e, pode-se dizer necessariamente, restringe o número de profissionais com tal formação, tendo em vista que o conhecimento prévio da LIBRAS é requisito essencial para o acesso à formação profissional.

Diante das exigências legais, muitas instituições veem-se numa "saia justa”, uma vez que há dificuldade para encontrar profissionais que preencham os requisitos para o cargo de docente de Libras, o que tem resultado em editais de seleção com as mais diversas exigências, as quais nem sempre contemplam o que pede a Legislação (TAVARES; CARVALHO, 2010).

Desse modo, nosso interesse em analisar a trajetória de formação dos professores de LIBRAS das Instituições de Ensino Superior - IES do Paraná parte do pressuposto de que grande parte desses docentes não possuam experiência na docência ou conhecimento linguístico da LIBRAS.

\section{METODOLOGIA}

Para analisar a trajetória de formação dos professores de Libras das Universidades Públicas Estaduais (UPEs) do Paraná utilizamos a base de dados de currículos disponível na Plataforma Lattes (http://lattes. cnpq.br/) que de acordo com os dados do próprio site tornou-se estratégica para a formulação das políticas do Ministério de Ciência e Tecnologia e de outros órgãos governamentais da área de ciência, tecnologia e inovação.

A escolha desse instrumento de análise se deu pela facilidade de acesso às informações de que necessitamos, dispensando o uso de termos de consentimento pessoais por parte dos professores analisados, uma vez que, todas as informações estão disponíveis para consulta, o que corrobora para a confiabilidade dos resultados.
Os currículos foram analisados em dezembro do ano de 2012, por isso as informações podem ter sido alteradas desde então. Foram analisados 9 currículos em 4 UPEs do Paraná.

Embora tivéssemos conhecimento de outros professores da disciplina de Libras atuantes nas Instituições estudadas e em outras UPEs do Paraná, cujos currículos não foram encontrados no período de nossa pesquisa, optamos por obedecer ao critério metodológico estabelecido previamente, ou seja, somente a análise da base de dados disponíveis na Plataforma Lattes.

As Universidades analisadas foram: Universidade Estadual de Maringá (UEM), Universidade Estadual de Londrina (UEL), Universidade Estadual do Oeste do Paraná (UNIOESTE) e Universidade Estadual do Norte do Paraná (UNIOESTE).

\subsection{ANÁLISE E DISCUSSÃO DOS DADOS}

A Formação Acadêmica foi nossa primeira categoria de análise, visto que, por se tratar de docência, espera-se que os docentes que possuem licenciatura ou Pedagogia estejam mais preparados para o trabatho educacional.

Para a formação acadêmica, analisamos o campo "Formação acadêmica/titulação", do currículo lattes de cada professor pesquisado. Os dados apontaram que $22 \%$ possuíam formação apenas em nível de graduação, enquanto a maioria, que corresponde a $78 \%$ desses professores possuíam especialização. Tendo em vista que se trata de docência em Ensino Superior, a formação apenas em nível de graduação, embora permitida, não confere ao docente o mesmo status dentro da academia.

Considerando que se trata de uma atividade de docência no Ensino Superior, consideramos que não basta possuir uma formação qualquer nesse nível de ensino, mas, uma formação inicial na 
área educacional se coloca como necessária para o exercício pleno da função.

Desse modo, analisamos se os professores possuíam formação inicial na área educacional e verificamos que $100 \%$ dos professores se enquadraram nessa categoria, sendo que $41 \%$ possuíam graduação em Letras/Libras; $17 \%$ possuíam Graduação em Letras e $42 \%$ eram formados em Pedagogia. Os currículos revelaram ainda que, alguns desses professores possuíam mais de uma graduação, entre as quais, formação em outras áreas do conhecimento, como Tecnologia em Design de Interiores, Gastronomia e Direito.

Outra categoria de análise se refere à formação específica na área da Surdez, visto que, a docência em Libras, na maioria das vezes, não se restringe ao ensino da Língua, mas contempla os conteúdos referentes às necessidades educacionais do aluno surdo (VITALIANO; DALL'ACQUA; BROCHADO, 2010).

Os dados demonstraram que $61 \%$ dos professores pesquisados possuíam especialização (concluída ou em andamento) na área da surdez e 39\% haviam cursado ou estavam concluindo Mestrado ou doutorado na área da Surdez.

De acordo com Quadros e Campello (2010, p.34) “O ProLIBRAS é um programa promovido pelo Ministério da Educação e desenvolvido por Instituições de Educação Superior (IES)", sendo assim, o Exame ProLIBRAS é um dos instrumentos de avaliação e um dos principais requisitos ao exercício da docência em Libras nas diversas IES. Desse modo procuramos verificar essa certificação pelos docentes pesquisados.

As análises demonstraram que $78 \%$ dos professores possuíam a certificação do Prolibras e os demais $22 \%$ não possuíam ainda essa certificação, porém possuíam certificação da Federação Nacional de Educação e Integração de Surdos- FENEIS, órgão também reconhecido para formação de profissionais em Libras. 0 fato de a maioria dos docentes possuírem certificado de proficiência em Libras caracteriza bom domínio e conhecimento dessa língua.

Ainda, levando em conta que a docência na disciplina de Libras não se restringe ao domínio da Língua, consideramos que a experiência em Educação e especialmente na Educação de Surdos pelo docente é de grande valor para a disciplina, que visa preparar futuros professores aptos a lidarem com as necessidades educacionais de alunos surdos.

Além disso, a experiência na docência em Libras também é extremamente necessária, pois, no decorrer da trajetória, o professor testa e adequa métodos e recursos que vão sendo cada vez mais aprimorados por ele, contribuindo para que sua prática seja cada vez mais eficaz.

Dentre os professores que compuseram nossa pesquisa, verificamos que $22 \%$ possuíam de 1 a 5 anos de experiência na docência, $33 \%$ possuíam de 5 a 10 anos nessa área e $45 \%$ já atuavam há mais de 10 anos como docentes. Além disso, 78\% desses professores já possuíam experiência considerável no ensino da Libras, de no mínimo 5 anos, atuando como professores ou instrutores dessa língua.

\section{CONSIDERAÇ̃̃ES FINAIS}

Consideramos que uma análise da qualidade do ensino de Libras nesse momento se coloca como necessária, tendo em vista que o prazo para atendimento ao Decreto 5626/05, no que se refere à inclusão da disciplina de Libras nas licenciaturas está encerrando. Entendemos que o professor constitui-se como peça chave no que diz respeito à seleção e condução do conhecimento necessário à formação de professores que irão atuar junto a alunos surdos.

Sendo assim, o presente artigo demonstrou por meio da análise de currículo dos professores de Libras de IES públicas paranaenses, que, apesar da urgência 
na demanda para a contratação de professores para a disciplina de Libras, essas universidades têm atentado para a qualidade dos professores.

A análise da trajetória de formação desses professores revelou o compromisso pela formação na área de atuação, visto que todos os pesquisados possuíam formação mínima em nível de especialização. Além disso, muitos desses profissionais possuíam mais de uma graduação, o que demonstra interesse pelo universo acadêmico.

A pesquisa evidenciou também que grande parte dos docentes atuantes nas IES, ministrando a disciplina de Libras, já possuía tempo de experiência considerável na educação, bem como no ensino de Libras, aspectos estes que consideramos favoráveis ao bom andamento da disciplina.

Por fim, consideramos que nosso pressuposto inicial, de que muitos profissionais não possuíam formação ou experiência suficiente para atuarem como docentes na disciplina de Libras, não se confirmou no universo pesquisado. Não descartamos, porém, a existência de professores nas condições consideradas inicialmente, mas em outros contextos. Cabe, desse modo, uma pesquisa mais ampla que contemple também as IES particulares e em diversos Estados brasileiros.

\section{REFERÊNCIAS}

BRASIL. Ministério da Educação e do Desporto. Secretaria de Educação Fundamental. Secretaria de Educação Especial. Parâmetros curriculares nacionais: Adaptações Curriculares. Brasília, DF: MEC/SEF/SEESP, 1998.

BRASIL. Decreto Federal n 5.626 de 22 de dezembro de 2005. Regulamenta a Lei no 10.436, de 24 de abril de 2002, e 0 art. 18 da Lei no 10.098, de 19 de dezembro de 2000. Diário Oficial da União, Brasília, DF, 2005.
CAIADO, K.; JESUS, D. M.; BAPTISTA, C.R . Educação Especial e Formação de Professores: Tendências e prioridades. In: CAIADO, K.; JESUS, D. M.; BAPTISTA, C.R.(Orgs.). Professores e Educação Especial: formação em foco. Porto Alegre: Mediação, 2011,v.2, p.7-16. CARVALHO, T. S. S.; TAVARES, I. M. S.. Inclusão escolar e a formação de professores para o ensino de libras (Língua Brasileira de Sinais): do texto oficial ao contexto. In: Pesquisa em Educação: desenvolvimento, ética e responsabilidade social, 2010, Maceio. V EPEAL - pesquisa em educação: desenvolvimento, ética e responsabilidade social, 2010.

IMBERNÓN, F. Formação docente e profissional: formar-se para a mudança e a incerteza. São Paulo: Cortez, 2009.

ISAIA, S. M. A. Desafio à docência superior: pressupostos a considerar. In: RISTOFF, Dilvo \& SEVEGNANI, Palmira (org.). Docência na educação superior. Brasília: Instituto Nacional de Estudos e Pesquisas Educacionais Anísio Teixeira, 2006. Coleção Educação Superior em Debate; v.5;

ISAIA, S.M.A.; BOLZAN, D.P.V. Construção da profissão docente/ professoralidade em debate: Desafios para a educação superior. In:CUNHA, M.I.(org.). Reflexões e práticas em pedagogia universitária. Campinas: $\mathrm{Pa}-$ pirus,2007.

NÓVOA, A. (Org.). Vidas de professores. 2. ed. [s.l.]: Porto Ed., 1995.

PARO, V. H. Educação como exercício de poder: crítica ao senso comum em educação. São Paulo: Cortez, 2008.

QUADROS, R; CAMPELLO, Ana Regina e Souza. A constituição política, social e cultural da língua brasileira de sinais- Libras. In: VIEIRA-MACHADO, Lucyenne Matos da Costa; LOPES, Maura Corcini. Educação de Surdos: Políticas, Línguas de Sinais, Comunidade e Cultura Surda. Santa Cruz do Sul: Edunisc, 2010. 
REBOUÇAS. Larissa Silva. A prioridade dos docentes surdos para ensinar a disciplina Língua Brasileira de Sinais (Libras) nas instituições de ensino superior após o decreto 5.626/2005. 2009. 171f. Dissertação de Mestrado - UFBA, Salvador, BA. 2009

ROMANOWSKI, Joana Paulin. Formação e profissionalização docente. 3.ed. rev. e atual. Curitiba: Ibpex, 2007.

SANTOS NETO, Elydio dos. Aspectos humanos da competência docente: Problemas e desafios para a formação de professores. In: SEVERINO, A. J; FAZENDA, I. C. A. Formação docente: Rupturas e possibilidades. Campinas: Papirus, 2002.
TAVARES, Ilda Maria S; CARVALHO, Tereza S. Santos de. Inclusão escolar e a formação de professores para o ensino de Libras (língua brasileira de sinais): do texto oficial ao contexto. Disponível em: <http://dmd2.webfactional.com/media /anais/INCLUSAO-ESCOLAR-E-A-FORMACAO-DE-PROFESSORES-PARA-O-ENSINO-DE-Libras-(LINGUA-BRASILEIRA-DE-SINAIS.pdf

VITALIANO, Célia Regina.; DALL’ ACQUA, Maria Julia C.; BROCHADO, Sônia Maria D. Língua Brasileira de Sinais nos currículos dos cursos de Pedagogia das Universidades Públicas dos Estados do Paraná e de São Paulo: caracterização da disciplina, Londrina: EDUEL, 2010.

Recebido em: 01 de agosto 2014

Avaliado em: 10 de fevereiro de 2015

Aceito em: 20 de março 2015
Recebido em: 1 de Agosto de 2014

Avaliado em: 10 de Fervereiro de 2015 Aceito em: 20 de Março de 2015

\footnotetext{
1. Possui Mestrado em Educação pela Universidade Estadual de Londrina (2012), graduação em Pedagogia e Letras. Especialista em Educação Especial (Unopar), Psicopedagogia (Esap) e Pós- Graduação (lato sensu) em LIBRAS. Docente da Universidade Estadual de Londrina- UEL e do Instituto de Educação Estadual de Londrina- IEEL. Tem experiência na área de Educação, com ênfase em Educação Especial, atuando principalmente nos seguintes temas: língua de sinais; filosofias educacionais; inclusão, língua, linguagem, comunidade surda, libras, inclusão escolar. surdez. formação de professores e libras, educação, inclusão. E-mail: josiane.almeida@yahoo.com.br

2. Pedagoga da Equipe de Educação Especial e Inclusão Educacional do Núcleo Regional de Educação de Maringá. E-mail: marisander@gmail.com
} 